\title{
PROPERTIES OF THE CAKE LAYER IN THE ULTRAFILTRATION OF POL YDISPERSE COLLOIDAL SILICA DISPERSIONS
}

\author{
N.H. Ramli ${ }^{1}$, A. Lord $^{2}$, L. Powell ${ }^{3}$, P.M. Williams ${ }^{4}$ \\ ${ }^{\text {I}}$ Faculty of Chemical and Natural Resources Engineering, University Malaysia Pahang, Tun Razak Highway, 26300 \\ Kuantan, Pahang, Malaysia \\ ${ }^{2}$ Multidisciplinary Nanotechnology Centre, Swansea University, Swansea, SA2 8PP, UK \\ ${ }^{3}$ Multidisciplinary Nanotechnology Centre, Swansea University, Swansea, SA2 8PP, UK \\ ${ }^{4}$ Multidisciplinary Nanotechnology Centre, Swansea University, Swansea, SA2 8PP, UK
}

\begin{abstract}
The properties of the cake layer formed during the ultrafiltration of polydisperse silica colloid using the Karman Cozeny equation have been studied and are compared to the experimental results obtained from SEM and AFM analysis. AFM analysis is used to give a direct comparison to SEM analysis in order to give a better understanding of the cake properties formed at different compositions and different $p H$ 's. The trend of the filtration rate of binary mixtures of silica particles (W3O and X30) were analysed and correlated to the results of the specific resistance obtained from SEM analysis. The study involves analysing the fouled membrane from the top view and from the cross sectional view. This present work has found that results from the SEM and AFM analysis corresponded to each other in terms of particle arrangement and the average cake thickness.
\end{abstract}

Keywords: polydisperse; cake resistance, colloidal -interaction ***

\section{INTRODUCTION}

Ultrafiltration is one of the pressure driven membrane separation processes which has been commercially used in many industries including the pharmaceutical, dairy, and dye industries. This type of the membrane process is capable of separating the solutes with a molecular weight greater than $1000 \mathrm{Da}$ (Coulson et al. 2002). Many works have been reported on the flux decline in ultrafiltration (Bowen and Jenner 1995; Bowen and Williams 1996a; Shen and Probstein 1977; Wijman et al. 1984) but only a few studies have been reported in the literature on modelling the behaviour of polydisperse feeds containing suspended colloidal particles (Dickinson 1979; Dickinson et al. 1988; McDonogh et al. 1998). Studies on the effect of polydispersity on the rate of filtration have been conducted by researchers in order to introduce a new parameter into the classic filtration model to consider for polydispersity effect (Mc Donogh et al. 1998, Dickinson, 1979). There are two approaches which can be used to include the effect of polydispersity which are the Resistance Model as introduced by McDonogh et al. (1998) or the Osmotic Pressure Model used by Dickinson (1979. In this work, the effect of polydispersity is examined in terms of a resistance model by estimating the specific cake resistance directly from the filtration rate and the cake layer thickness analysis under the SEM.

The application of the SEM for membrane characterisation has played an important role in membrane development and fouling control. SEM analysis enables investigation of the separation characteristics and the mechanical strength of the membrane, which are controlled by the surface morphology and chemical make up of the membrane. Performance of the developed membrane can be optimized by knowing some useful information observed in a SEM. Many works have been reported on the SEM analysis for membrane characterization (Kim et al. 2006; Madaeni 1998a; Madaeni 1998b; Meng et al. 2005; Schossig-Tiedemann and Paul 2001; Wickramasinghe et al. 2009; Ziel et al. 2008).

A number of studies have been conducted on AFM characterization related to membrane analysis (Bessibres et al. 1996; Binning et al. 1982; Bowen et al. 1996a; Bowen et al. 1996b; Bowen et al. 1998a; Bowen et al. 1998b). The AFM can be used to give high resolution nanometer scale images of the topography of a range of surfaces with little surface preparation and no surface coating. AFM imaging technology has been utilised for the quantification of surface morphology, pore size distributions and surface roughness for various types of membranes, such as NF, RO and UF (Bowen and Doneva, 2000, Norberg et al. 2007, Vrijenhoek et al. 2001). However no study has investigated the crosssection of flat sheet membrane by AFM, with the majority of research groups utilising SEM for cross-sectional membrane characterisation. Khulbe et al. (2006) examined the cross-section of polyetherimide hollow fibers prepared by two methods using AFM, however due to difficulties in sample preparation only $3 \mu \mathrm{m}$ images of the fibers could be obtained. In this present study, the morphology, roughness and peak-to-valley height of the cross-section of the flat sheet membrane complete with cake layers were studied by AFM and compared to the findings observed from the SEM analysis. 


\section{THEORETICAL ASPECTS}

\subsection{Cake Resistance Model}

The basic flux equation is given by equation 1 in which flux decline is controlled by applied pressure difference and resistance.

$$
J=\frac{|\Delta P|-|\Delta \pi|}{\mu\left(R_{m}+R_{c}\right)}=\frac{1}{A_{m}}\left(\frac{d V}{d t}\right)
$$

However, many researchers agreed that osmotic pressure can be ignored if the cake resistance is already considered in the model (Bowen and Jenner, 1995, Bowen and Williams 1996). The cake resistance model is described by equation (2) where the osmotic pressure term is eliminated from equation 1

$$
J=\frac{|\Delta p|}{\mu\left(R_{m}+R_{s}\right)}=\frac{1}{A_{m}}\left(\frac{d V}{d t}\right)
$$

where,

$$
R_{c}=\frac{\alpha V C_{b}}{A_{m}}
$$

The relationship between Darcy's Law and Carman Kozeny is used to express $\alpha$, in which $\alpha$ is the specific resistance of the deposited mass.

$$
\alpha=\frac{180}{\rho_{p} d_{s}^{2}}\left(\frac{1-\varepsilon}{\varepsilon^{3}}\right)
$$

where $\varepsilon$ is void volume, $\rho_{p}$ is the particle density, $d_{s}$ is the mean particle diameter, $V$ and $A_{m}$ are the total filtered volume and membrane area respectively.

Wutzel and Samhaber (2009) have modified the filtration theory of equation to take into account the cake thickness $\delta$, formed during the process

$$
\frac{1}{A_{m}} \frac{d V}{d t}=\frac{\Delta P}{\eta\left(\alpha_{c} \delta+R_{m}\right)}
$$

where $\alpha_{c}$ represents the specific resistance of the cake layer and $R_{m}$ is the resistance of the membrane. The thickness of the porous cake layer can rewritten as,

The thickness of the porous cake layer can rewritten as,

$$
\delta=\frac{m}{\rho_{p} A_{m}(1-\varepsilon)}
$$

where $m$ is the mass of the layer, $\rho_{p}$ is the particle density and $\varepsilon$ is the porosity of the layer. $\alpha$, the specific resistance of the deposited mass is defined by the Carman Kozeny law (Carman, 1938) as described in Equation (4).

However equation (4) is only applicable for monodisperse system. Endo and Alonso (2001) have proposed a theoretical model of cake filtration in the laminar flow regime which is applicable for polydisperse systems. The model assumes the cake consists of non-spherical particles with a log-normal size distribution. This results in an alteration of Equation (4) to:

$$
\alpha=\frac{180}{\rho_{p}} \frac{\kappa}{d_{v g}^{2} \exp \left(4 \ln ^{2} \sigma_{g}\right)} \frac{(1-\varepsilon)}{\varepsilon^{3}}
$$

where $\kappa$ is a shape factor (which is equal to 1 for spheres), $d_{v g}$ is the geometric mean diameter of $d_{p}$ on a number basis and $\sigma_{g}$ is the geometric standard deviation. If the particles are monodisperse Equation (7) becomes identical to Equation (4).

The parameters, $d_{v g}$ and $\sigma_{g}$ can be calculated using:

$$
\begin{gathered}
d_{v g}=\exp \left(\frac{\sum n_{i} \ln d_{p i}}{\sum n_{i}}\right) \\
\sigma_{g}=\exp \left(\sqrt{\frac{\sum n_{i}\left[\ln \left(d_{i} / d_{v g}\right)\right]^{2}}{\sum n_{i}}}\right)
\end{gathered}
$$

The specific resistance, $\alpha$ is calculated from the slope of the plot of $t / V$ versus $V$, where the gradient is defined as:

$$
\text { gradient }=\frac{\mu C_{b} \alpha_{c}}{2 A_{m}^{2} \Delta P}
$$

Therefore, porosity can be predicted by using Equations (7)(10), and the porosity can be substituted into equation (6) to estimate the thickness of the cake layer form in the filtration process. The combination of cake thickness and the specific cake resistance can be used to calculate the cake resistance. Note that, cake resistance $R_{c}$ is described in Equation (3), and the cake volume term in Equation (3) shown above can be determined as

$$
V=\delta \times A_{m}
$$

Substituting Equation (11) into Equation (3) yields:

$$
R_{c}=\alpha_{c} \delta C_{b}
$$


The aim of the presents work is to investigate the influence of polydispersity to the cake resistance properties. For these reasons the fouled membrane is observed under the SEM and AFM to investigate the particle arrangement and the thickness of the cake layer deposited on the membrane due to the variation in the feed composition and $\mathrm{pH}$ change.

\section{EXPERIMENTAL}

\subsection{Silica Dispersion}

Sodium chloride electrolyte solutions were made by dissolving a weighed amount of sodium chloride, obtained from Fisons Scientific Equipment (Grade:- Fisons AR), in high purity water (produced by a Millipore Elix 3 system) to make a solution of the required ionic strength. The ionic strength of the electrolyte used was verified from specific conductivity measurements performed using a Portec PI8140 digital conductivity meter in connection with a Philips conductivity cell (type: 4550/60).

The colloidal particles used were W30 and X30 colloidal silica (purchased from Morrisons Gas Related Products Ltd). These came as liquid dispersions with the following properties: concentration $\approx 30 \%$ by weight, dispersion medium $\approx 0.03 \mathrm{M} \mathrm{NaCl}$ solution (plus other stabilizers) at $\mathrm{pH} \approx 9.5$, particle diameter $\mathrm{X} 30 \approx 15 \mathrm{~nm}, \mathrm{~W} 30 \approx 50 \mathrm{~nm}$. The exact concentration of this stock solution was determined in the following manner. Five petri dishes were taken and weighed using an electronic balance (Mettler Toledo P303 Delta Range, accurate to $\pm 0.001 \mathrm{~g}$ ). A known amount of the stock silica solution was then added to each petri dish. The dishes were then placed in an oven set at $120^{\circ} \mathrm{C}$ and left overnight to dry. The dishes were then weighed again the following day and the difference between this new weight and the clean petri dish weight was found. This corresponds to the mass of dry silica in the solution. The mass weight $\%$ was then found by dividing the weight of dry silica by the total solution weight. Finally, the average value of the five measurements was taken and used subsequently as the concentration of the stock silica solution. Dilutions of this stock solution were made by adding known amounts of $0.03 \mathrm{M} \mathrm{NaCl}$ to a known mass of the stock silica solution. The $\mathrm{pH}$ of the final silica solution was adjusted to the desired value by the dropwise addition of $\mathrm{NaOH}$ and $\mathrm{HCl}$ (both of Grade:- Fisons AR). The $\mathrm{pH}$ measurements were carried out using a Philips PW 9421 digital high precision $\mathrm{pH}$ meter ( $\mathrm{pH}$ resolution 0.01 ) in connection with a Russell CMAWL/4/5 pH probe.

\subsection{Size Measurements}

Dynamic light scattering measurements were performed with a Malvern HPPS system (Malvern Instruments Limited, UK). The light source was an Argon laser operating with vertically plane polarised light at a wavelength of $488 \mathrm{~nm}$. All the dynamic light scattering measurements were carried out at a low laser power $(\sim 13.3 \mathrm{~mW})$, so the results are not influenced by local heating of the samples which would be caused by use of a more powerful beam. The scattering angle used was $90^{\circ}$. The temperature of the samples was automatically kept at $25.0 \pm 0.1{ }^{\circ} \mathrm{C}$. Prior to each experiment, the measurement cell was flushed with highpurity water to remove dust in the cell. Dynamic light scattering measurements were performed on $4 \mathrm{~g} / \mathrm{L}$ silica dispersions in $0.03 \mathrm{M} \mathrm{NaCl}$ at various $\mathrm{pH}$ values. Only solutions containing $100 \% \mathrm{~W} 30$ or $100 \%$ X30 were used for these experiments. The data measured was analysed according to BS 3406 (1997) in order to determine the particle size.

\subsection{Zeta Potential Measurements}

The same silica dispersions as used for the size measurements were used for the electrophoretic mobility measurements. Electrophoretic mobility measurements were made using a Zetasizer 2000 (Malvern Instruments, UK). Electrophoretic mobility values were converted to zetapotentials using the WinMobil programme (Department of Mathematics, University of Melbourne) which is an extended implementation of an advanced theory of electrophoresis (O’Brien and White, 1978).

\subsection{Filtration}

Filtration measurements were carried out using a $50 \mathrm{~mL}$ filtration cell (Amicon Corp., Model 8050) connected to a reservoir with a maximum capacity of $250 \mathrm{~mL}$. The effective membrane area was $13.4 \mathrm{~cm}^{2}$. The system was pressurised with nitrogen gas and the cell was not stirred. The temperature of the system was kept constant at $25.0 \pm$ $0.1{ }^{\circ} \mathrm{C}$ via a water jacket on the filtration cell and a water bath around the reservoir. The filtration time was coupled to the amount of permeate collected - experiments were stopped usually after $25-30 \mathrm{~mL}$ of permeate was collected. The total filtration time was therefore in the range of $1-3$ hours, depending on the solution conditions. Rates of filtration were determined by continuously weighing the filtrate on an electronic balance connected to a microcomputer.

NADIR polyethersulphone membranes of molecular weight cut-off 4000D were obtained from MICRODYN-NADIR $\mathrm{GmbH}$ (Germany). Before use the membrane was cleaned using pure water and then soaked for at least 16 hours. The hydraulic resistance of the NADIR 4000D membrane discs was determined by filtration of pure electrolyte solution through the membrane. The clean water flux or solvent flux rates are determined by filtering the water/electrolyte alone through a fresh membrane at five different pressures (50, $100,200,300$ and $400 \mathrm{kPa}$ ) until $20 \mathrm{~mL}$ of permeate sample is collected at each pressure.

Filtrations were then carried out on silica solutions containing a total silica concentration of $4 \mathrm{~g} / \mathrm{L}$. These solutions consisted of a $0.03 \mathrm{M} \mathrm{NaCl}$ electrolyte with the following mixing ratio of $\mathrm{X} 30$ :W30 by weight: (i) $100 \%$ $\mathrm{X} 30$, (ii) $100 \% \mathrm{~W} 30$, (iii) $20 \%: 80 \%$ (iv) $40 \%: 60 \%$, (v) 60\%:40\% and (vi) 80\%:20\%. The filtration experiments were repeated at least three times to confirm the validity of the experimental data. 


\subsection{SEM Analysis}

\subsubsection{Solution Properties}

The properties of the feed solution for W30 and X30 solutions were observed under a SEM machine (Model S4800 Hitachi). A drop of the diluted solution (with a concentration $\approx 0.1 \mathrm{~g} / \mathrm{L}$ ) was placed onto a silicon wafer and spread evenly using a spin coater (GME Limited, PRS14E). The sample was dried using a hot plate (Stuart Scientific) before being imaged with the SEM. A low concentration of solution was required for the purpose of imaging the characteristics of the silica particles on the silicon wafer surface in order to reduce charging problems during the imaging process so that a high resolution image can be obtained. The measurement of the individual particle size of silica particles under the SEM can also be done easily as the low concentration solution avoids particles from being clumped to each other.

\subsubsection{Clean Membrane Properties}

The clean NADIR 4000D MWCO membrane used in the dead-end filtration experiments was imaged under the SEM. A fresh and cleaned membrane was initially soaked overnight in water. The membrane was then compacted in a filtration experiment using a $\mathrm{NaCl}$ electrolyte solution of $0.03 \mathrm{M}$ concentration and pressurised at $200 \mathrm{kPa}$ until $15 \mathrm{~mL}$ of permeate solution was collected. The membrane was removed and square fragments with an area of several square milimeters were cut out of the membrane. Cutting of the membrane was greatly aided by freezing in liquid nitrogen for a few minutes which makes the sample brittle. The square fragments of membrane were then adhered to the SEM's aluminium sample stub using standard microscopy silver paint and dried at room temperature.

\subsubsection{Fouled Membrane Properties}

At the end of the dead end filtration experiments where colloidal silica solutions were used as the feed solution, the fouled membrane was removed from the filtration cell. The filtration was stopped when the volume of permeate solution reached about 15 to $20 \mathrm{~mL}$. This ensured that the cake formed under constant pressure. Again, the sample was frozen in liquid nitrogen, fractured into small fragments and stuck on the SEM sample stub using silver paint with the surface of the cake layer facing upwards. As the sample consisted of nonconductive material, the deceleration mode at $1.5 \mathrm{kV}$ current was applied when observing the sample under the SEM to reduce the charging problem. Topographical and cross sectional imaging analysis of the fouled membrane was carried out at different feed compositions depending on the trend of filtration seen in the previous work (Ramli and Williams 2012, Ramli 2012)

\subsection{AFM Analysis}

Similar to SEM, AFM was used to observe the fouled membrane from two different perspectives which are the topographical view and cross sectional view. The properties of the solutions (W30 and X30) and the clean membrane were imaged under the AFM initially. This preliminary experimental work was required in order to get information on the active layer and support layer of the membrane along with the silica properties.

\subsubsection{Experimental Procedure}

The Dimension 3100 AFM (Digital Instruments - Veeco Metrology group, Santa Barbara, California) and non contact cantilevers (RTESPA, Veeco) were used for crosssectional membrane imaging. The membrane images were obtained using tapping mode, at a scan rate of $0.5 \mathrm{~Hz}$ and an image resolution of 512 × 512 pixels. However, for the largest scan size of $60 \times 60 \mu \mathrm{m} 2$, a scan rate of $0.3 \mathrm{~Hz}$ was used to achieve a higher quality image. The captured images were analysed using Nanoscope offline software. The mean measurements of the software computed Peak-to-Valley height and Root-mean-square (RMS) roughness, from eight $10 \times 10 \mu \mathrm{m} 2$ images of the silica covered membrane.

\subsubsection{Solution Properties}

Properties of the W30 and X30 particles were observed under the AFM. A drop of the stock silica solution was diluted with $300 \mathrm{~mL}$ of deionised water. Then a drop of this diluted solution was taken and deposited on a glass slide and dried at room temperature before being analysed under the AFM.

\subsubsection{Clean Membrane Properties}

Analysis of the clean membrane under the AFM is straight forward, where the dry membrane was cut into square fragments with an area of several square milimeters and stuck on a glass slide using double sided tape with the active layer facing upwards.

\subsubsection{Fouled Membrane Properties}

For cross sectional analysis the sample was prepared in the same way as the SEM samples by fracturing a small part of the membrane in liquid nitrogen. The cross sectional sample was fixed in a vertical position on the glass slide using double sided tape, with the exposed part of the membrane facing upwards. Then the membrane sample was sandwiched between two glass slides to stabilize the sample for AFM imaging (Ramli 2012).

\section{RESULTS AND DISCUSSION}

\subsection{Solution Characteristic}

The particle size and zeta potential results are shown in Table 1 for the X30 and W30 colloidal silica. Table 1 shows that W30 is approximately 3.3 times the size of X30. Ten measurements were made on each sample at $\mathrm{pH} \mathrm{4,6}$ and 9 and the average of all these measurements are shown in Table 1, as there is no appreciable difference in size between the measurements made at the three different $\mathrm{pH}$ values. Table 5.1 also shows the zeta potentials measured at the different $\mathrm{pH}$ values. The zeta potential values are an average of at least 35 measurements on each sample. The magnitude of the zeta potential of $\mathrm{W} 30$ at $\mathrm{pH} 9$ is appreciably higher than the value for $\mathrm{X} 30$ (by $10 \mathrm{mV}$ ), whilst at $\mathrm{pH} 6$ the values are similar. 
Table 1: Size and zeta potential results for X30 and W30 colloidal silica in a $0.03 \mathrm{M} \mathrm{NaCl}$ electrolyte solution (the \pm values show the standard deviation away from the average value).

\begin{tabular}{|ll|l|l|l|}
\hline & & & X30 & W30 \\
\hline $\begin{array}{l}\text { Particle } \\
(\mathbf{n m})\end{array}$ & Diameter & & $15.6 \pm 0.9$ & $51.7 \pm 1.7$ \\
\hline $\begin{array}{l}\text { Zeta } \\
(\mathbf{m V})\end{array}$ & Potential & pH 4 & $-15.9 \pm 1.4$ & $-7.2 \pm 1.2$ \\
\hline & & pH 6 & $-29.4 \pm 3.3$ & $-29.8 \pm 1.4$ \\
\hline & pH 9 & $-89.3 \pm 5.9$ & $-98.3 \pm 7.3$ \\
\hline
\end{tabular}
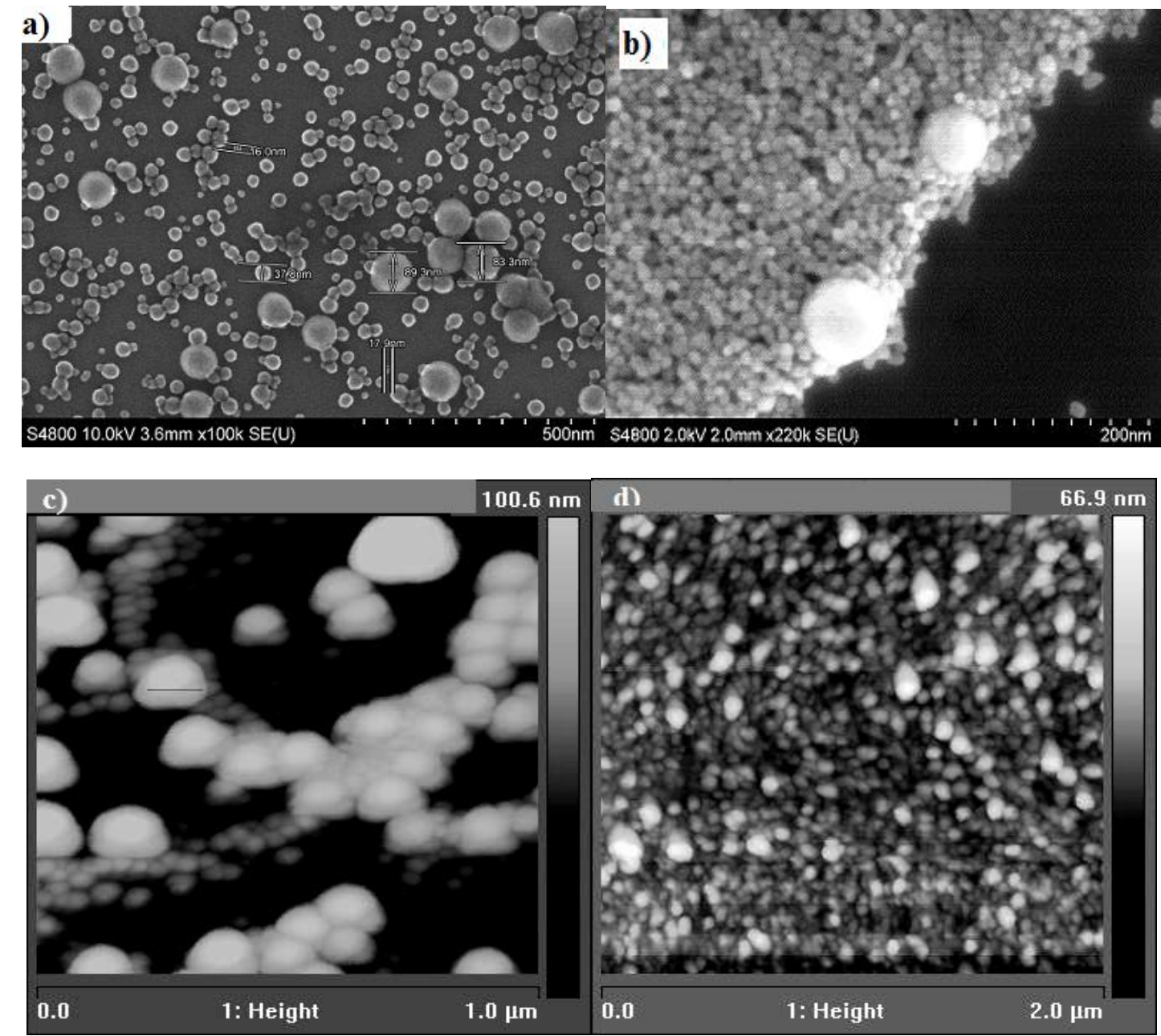

Fig 1: Solution characteristics for W30 and X30 viewed under the SEM for a) W30 and b) X30, and the AFM for c)W30 and d) X30

This finding contradicts the work by Bowen and Jenner (1995) who assumed that the W30 solution is a monodisperse system, a result which was also found within the work in Ramli and Williams (2012). The reason for this is due to the limitations in using dynamic light scattering to analyse the particle size in the solution

\subsection{Filtration Results}

Figure 2(a)-(c) depicts the normalized filtration rate of binary mixtures $\mathrm{W} 30$ and $\mathrm{X} 30$ silica at $\mathrm{pH} 9$, $\mathrm{pH} 6$ and $\mathrm{pH} 4$, respectively (Ramli and Williams 2012). Normalized data is
Figure 1 (a-d) illustrates the images of silica particles contained in W30 and X30 solutions as viewed under SEM (Figures 1a and b) and AFM (Figure 1c and d). Figure 1a\&c shows that the W30 solution is found to be polydisperse in nature from the SEM and AFM results.$$
\text { d) }
$$ 

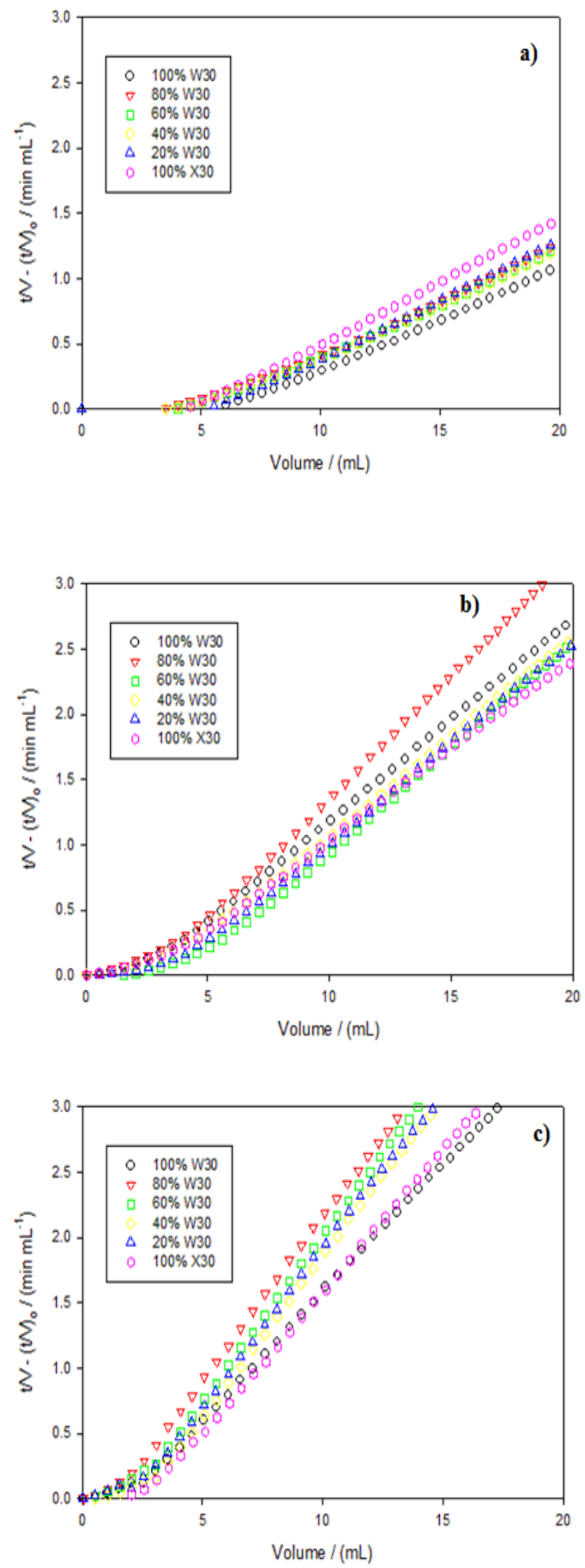

Fig 2: Normalised flux for the filtration of silica binary mixtures (X30 and $\mathrm{W} 30$ ) at a) $\mathrm{pH} \mathrm{9,} \mathrm{b)} \mathrm{pH} 6$ and c) $\mathrm{pH} 4$
A different pattern of filtration rates is seen for the filtration at $\mathrm{pH} 6$ as shown in Figure 2(b). The fastest filtration is given by $100 \%$ composition of $\mathrm{X} 30$. The filtration rate of W30 is slower but is not the slowest value seen. When a small amount of X30 is added to W30 i.e. $20 \%$ by weight, the filtration rate of this solution is markedly slower than the filtration rates of $100 \% \mathrm{~W} 30$ and $100 \%$ X30 (Ramli and Williams 2012). This is likely to be due to the filling of interstices in W30 filter cake in the bidisperse mixture (McDonogh et al. 1998).

Figure 2(c) shows the normalized results for the binary mixtures of X30 and W30 silica at pH 4. The 100\% W30 and $100 \% \times 30$ give similar filtration rates in this case. Again, as with the data at $\mathrm{pH}$ 6, addition of a small amount of X30 to the feed solution causes a sharp decrease in the filtration rate, most likely due to the reasons as discussed for pH 6. The $80 \%$ and $60 \%$ by weight $\mathrm{W} 30$ feed solutions give similar slow filtration rates, whilst the $40 \%$ and $20 \%$ by weight W30 feed solutions gave intermediate filtration rates between the extremes.

\subsection{Properties of the Cake Layer under SEM}

\section{Analysis}

Figures 3 (a)\&(d) illustrate SEM images of the clean and fouled membrane. The reason for imaging the clean membrane prior to use is in order to get information on the active layer and support on the membrane under the SEM. Therefore, the cake thickness measurement does not include the support layer together. In Figure 3(c), the thickness of the cake layer can be seen by knowing that the support layer has more porous and uniform structure. In this work, the same imaging procedures were repeated at each condition (at $\mathrm{pH} 4,6$ and 9) and are summarised in the Tables (1)-(3). This analysis was only carried out at the compositions which gave the maximum, intermediate and minimum filtration rates as shown in Figures 2(a)-(c).

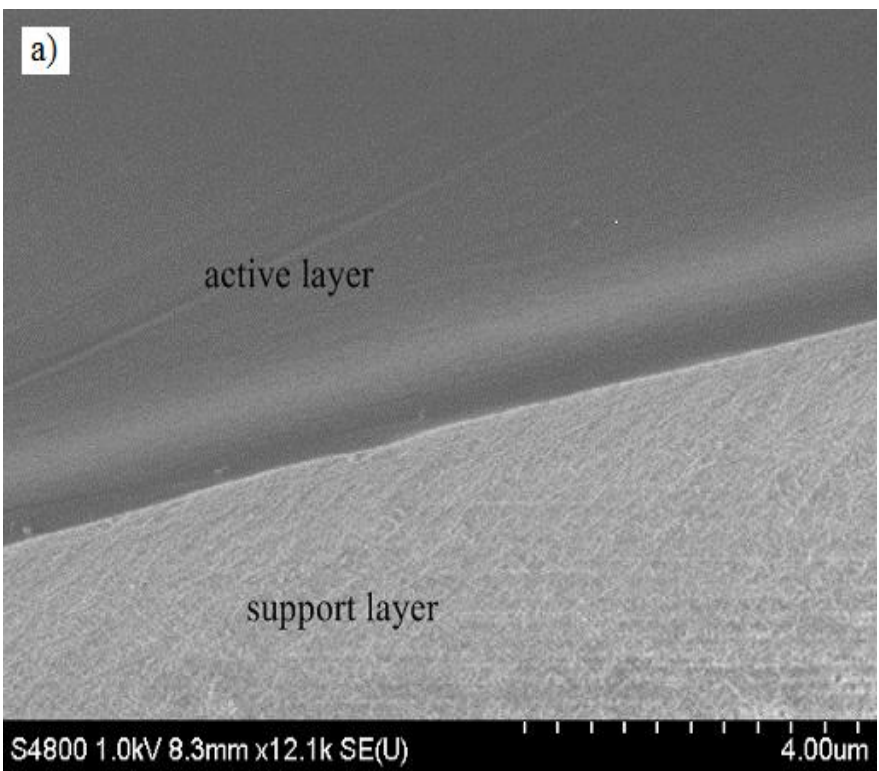




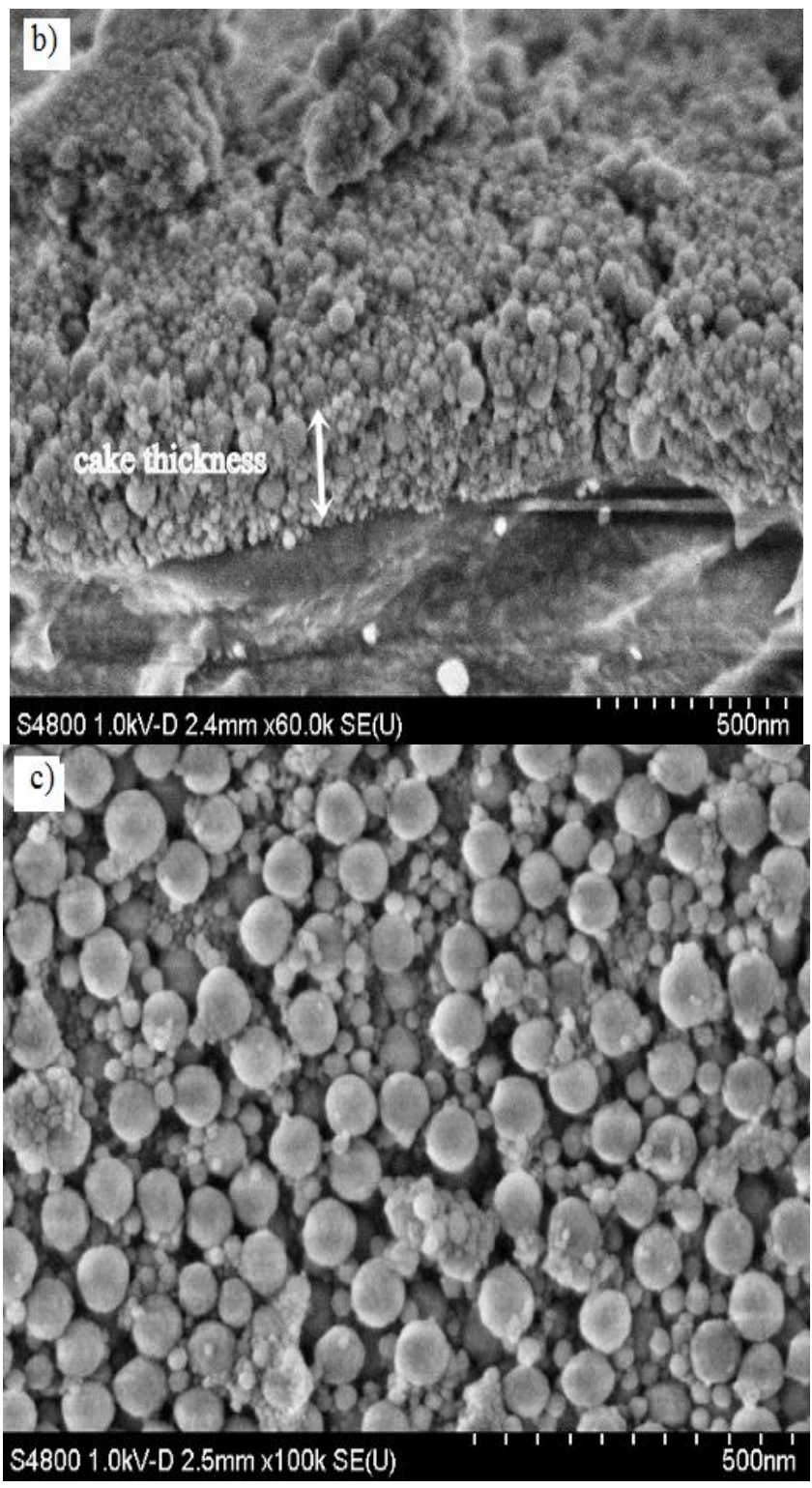

Fig 3: SEM images of clean and fouled membrane; a)clean b) cake thickness and c) silica particle arrangement

\subsubsection{At pH 9}

For $\mathrm{pH}$ 9, SEM observation is carried out for three feed compositions which are; 100\%W30, 20\%W30and 80\%X30, and $100 \% \times 30$ in order to investigate significant effect of the cake properties on the filtration rate. Table 2 summarizes the overall properties of the cake measured experimentally and predicted from theory at $\mathrm{pH} 9$ at various different compositions. There is a huge difference between the calculated and measured cake thickness shown in Table 2. The measured thickness is much less than the predicted value calculated from the mass balance. There are two reasons why this might be the case. First, the cake might have been washed off during the sample preparation, or came off from the surface when the membrane has been fractured in liquid nitrogen during the sample preparation. Second, there is also a possibility that the cake shrinks under the vacuum pressure in the SEM machine. The estimated thickness was calculated based on the mass balance for filtering $20 \mathrm{~mL}$ of the feed through the membrane without considering any other phenomena.

The cake resistance calculated from the mass balance and filtration rate data are quite comparable to each other and both resistances increase as the X30 concentration increased in the feed solution. This corresponds with the filtration trends shown in Figure 2(a) where 100\% W30 gives the fastest filtration rate at $\mathrm{pH} 9$. However, the resistance calculated from the cake thickness (thickness from SEM images) contradicts these trends. This is very likely to be due to the difficulty of preparing the samples for SEM image observation.

Table 2: Properties of the cake layer obtained at $\mathrm{pH} 9,0.03 \mathrm{M} \mathrm{NaCl}$.

\begin{tabular}{|l|l|l|l|l|l|l|}
\hline & & & \multicolumn{4}{|l|}{$\begin{array}{l}\text { Cake Resistance } \\
\boldsymbol{R}_{\boldsymbol{c}}\left(\boldsymbol{m}^{-1}\right)\end{array}$} \\
\cline { 5 - 7 } Sample & $\begin{array}{l}\text { Estimated } \\
\text { Porosity } \\
\boldsymbol{\varepsilon}\end{array}$ & $\begin{array}{l}\text { Estimated } \\
\text { Thickness } \\
\boldsymbol{\delta}(\boldsymbol{\mu m})\end{array}$ & $\begin{array}{l}\text { Actual } \\
\text { Thickness } \\
\boldsymbol{\delta}(\boldsymbol{\mu m})\end{array}$ & $\begin{array}{l}\text { from mass } \\
\text { balance } \\
\times 10^{13}\left(\mathrm{~m}^{-1}\right)\end{array}$ & $\begin{array}{l}\text { from } \\
\text { filtration } \\
\text { rate } \\
\times 10^{13}\left(\mathrm{~m}^{-1}\right)\end{array}$ & $\begin{array}{l}\text { from } \\
\text { cake } \\
\text { thickness } \\
\times 10^{11}\left(\mathrm{~m}^{-1}\right)\end{array}$ \\
\hline $100 \% \mathrm{~W} 30$ & 0.303 & 38.93 & $0.22 \pm 0.04$ & 4.66 & 5.54 & 2.63 \\
\hline $20 \% \mathrm{~W} 30$ & 0.552 & 60.57 & $0.26 \pm 0.03$ & 5.07 & 6.62 & 2.18 \\
\hline $0 \% \mathrm{~W} 30$ & 0.549 & 60.17 & $0.13 \pm 0.02$ & 5.43 & 6.82 & 1.17 \\
\hline
\end{tabular}




\subsubsection{At pH 6}

SEM analysis for cake formation at pH 6 was carried out at four different compositions which were 100\% W30, 80\% W30, 20\% W30 and $100 \%$ X30.

Table 3: Properties of the cake layer obtained at $\mathrm{pH} 6,0.03 \mathrm{M} \mathrm{NaCl}$

\begin{tabular}{|c|c|c|c|c|c|c|}
\hline \multirow[b]{2}{*}{ Sample } & \multirow[b]{2}{*}{$\begin{array}{l}\text { Estimated } \\
\text { Porosity } \\
\varepsilon\end{array}$} & \multirow[b]{2}{*}{$\begin{array}{l}\text { Estimated } \\
\text { Thickness } \\
\delta(\mu \mathrm{m})\end{array}$} & \multirow[b]{2}{*}{$\begin{array}{l}\text { Actual } \\
\text { Thickness } \\
\delta(\mu \mathrm{m})\end{array}$} & \multicolumn{3}{|c|}{$\begin{array}{l}\text { Cake Resistance } \\
R_{c}\left(m^{-1}\right)\end{array}$} \\
\hline & & & & $\begin{array}{l}\text { from mass } \\
\text { balance } \\
\times 10^{13}\left(\mathrm{~m}^{-1}\right)\end{array}$ & $\begin{array}{l}\text { from } \\
\text { filtration } \\
\text { rate } \\
\times 10^{13}\left(\mathrm{~m}^{-1}\right)\end{array}$ & $\begin{array}{l}\text { from } \\
\text { Cake } \\
\text { thickness } \\
\times 10^{11}\left(\mathrm{~m}^{-1}\right)\end{array}$ \\
\hline $100 \% \mathrm{~W} 30$ & 0.228 & 35.15 & $0.32 \pm 0.05$ & 11.4 & 10.3 & 10.4 \\
\hline $80 \% \mathrm{~W} 30$ & 0.354 & 42.01 & $0.51 \pm 0.08$ & 13.7 & 12.1 & 16.7 \\
\hline $20 \% \mathrm{~W} 30$ & 0.447 & 49.07 & $0.34 \pm 0.01$ & 11.8 & 9.34 & 8.15 \\
\hline 0\%W30 & 0.471 & 51.3 & $0.11 \pm 0.05$ & 10.1 & 9.67 & 2.18 \\
\hline
\end{tabular}

Table 3 summarizes the cake properties at various compositions for $\mathrm{pH} 6$ in a $0.03 \mathrm{M} \mathrm{NaCl}$ electrolyte solution. Again, the estimated thickness was much bigger than the measured thickness. Overall, the cake seen at this $\mathrm{pH}$ was more compact when compared to the cake observed at $\mathrm{pH} 9$. Madaeni (1998b) reported that increasing pH causes a slight increase in flux, due to the extra charge gained by the particles when the $\mathrm{pH}$ increases causing greater porosity in the cake leading to a reduction in resistance. From the resistances calculated in Table 3, the maximum value of resistance was obtained for the $80 \% \mathrm{~W} 30$ sample, which gave the slowest filtration (see Figure 2(b)). This can be explained by the filling interstices effect which was more prominent at this composition due to the difference in particle size distribution and surface charge effects present between the particles. The estimated porosity increases with an increase in the X30 composition as shown in Table 3. This was correlated to the reduction in cake resistance calculated from the cake measurement, theory and flux experiments due to the increase in voids when more X30 particles are present.

\subsubsection{At pH 4}

For $\mathrm{pH} 4$, the trend of filtration was similar to the trend seen at $\mathrm{pH} 6$ (see Figures 2(b\&c). Therefore, samples with the same compositions which are $100 \% \mathrm{~W} 30,80 \% \mathrm{~W} 30,20 \%$ $\mathrm{W} 30$ and 100\% X30 were observed under the SEM.

Table 4: Properties of the cake layer obtained at $\mathrm{pH} 4,0.03 \mathrm{M} \mathrm{NaCl}$.

\begin{tabular}{|l|l|l|l|l|l|l|}
\hline & & & \multicolumn{5}{|l|}{$\begin{array}{l}\text { Cake Resistance } \\
\text { Sample }\end{array}$} & $\begin{array}{l}\text { Estimated } \\
\text { Porosity } \\
\boldsymbol{\varepsilon}\end{array}$ & $\begin{array}{l}\text { Estimated } \\
\text { Thickness } \\
\boldsymbol{\delta}(\boldsymbol{\mu m})\end{array}$ & $\begin{array}{l}\text { Actual } \\
\text { Thickness } \\
\boldsymbol{\delta}(\boldsymbol{\mu})\end{array}$ & \begin{tabular}{l}
$\boldsymbol{R}_{\boldsymbol{c}}\left(\boldsymbol{m}^{-1}\right)$ \\
\cline { 4 - 7 }
\end{tabular} & $\begin{array}{l}\text { from mass } \\
\text { balance } \\
\times 10^{13}\left(\mathrm{~m}^{-1}\right)\end{array}$ & $\begin{array}{l}\text { from } \\
\text { filtration } \\
\text { rate } \\
\times 10^{13}\left(\mathrm{~m}^{-1}\right)\end{array}$ & $\begin{array}{l}\text { from } \\
\text { Cake } \\
\text { thickness } \\
\times 10^{11}\left(\mathrm{~m}^{-1}\right)\end{array}$ \\
\hline $100 \% \mathrm{~W} 30$ & 0.215 & 34.57 & $0.12 \pm 0.02$ & 14.7 & 12.5 & 5.09 \\
\hline $80 \% \mathrm{~W} 30$ & 0.329 & 40.44 & $0.79 \pm 0.09$ & 17.9 & 17.4 & 35.0 \\
\hline $20 \% \mathrm{~W} 30$ & 0.405 & 45.61 & $0.41 \pm 0.08$ & 17.1 & 12.7 & 15.4 \\
\hline $0 \% \mathrm{~W} 30$ & 0.418 & 46.63 & $0.15 \pm 0.02$ & 16.2 & 11.9 & 5.21 \\
\hline
\end{tabular}


Table 4 summarizes the cake properties observed at $\mathrm{pH} 4$ at various compositions. As expected, the resistance calculated from the theory and filtration experiment has shown that the resistance at $80 \%$ and $60 \% \mathrm{~W} 30$ were very close to each other and gave the maximum resistance when compared to the other compositions. This prediction agrees well with the filtration rate results shown in Figure 2(c) where these two values gave the slowest filtration rate. The same happened with the resistance measured from the cake thickness where the $80 \% \mathrm{~W} 30$ solution gave the maximum value compared to the other compositions. However, the data for the cake resistance at $60 \% \mathrm{~W} 30$ is not available as no cake thickness measurement has been made at this composition as a similar filtration rate to the $80 \% \mathrm{~W} 30$ results was shown (see Figure 2(c)).

The thickness measurement of the cake layer shows that at $80 \%$ W30 composition at pH 4, the cake layer thickness was $55 \%$ greater when compared to the cake layer obtained at $\mathrm{pH} 6$ for the same composition. Hence, the porosity calculated at this $\mathrm{pH}$ is even smaller when compared to $\mathrm{pH}$ 6. This was caused by the agglomeration phenomenon between the smaller particles compared to the filling void effect, resulting in the cake becoming thicker and more porous. For these reasons the resistance calculated at $\mathrm{pH} 4$ is greater than the resistance calculated at $\mathrm{pH} 6$. However, the estimated thickness from theory has shown that the cake obtained at $\mathrm{pH} 4$ is thinner than that obtained at $\mathrm{pH} 6$. This was due to the estimation by the theory being calculated only via the mass balance and measured porosity without considering any other phenomenon such as particle interaction and void filling effects which can effect the cake layer formation.

\subsection{Properties of the Cake Surface under the AFM}

\section{Analysis}

For $\mathrm{pH} 9$ and $0.03 \mathrm{M} \mathrm{NaCl}$, the AFM image analyses are carried out for $100 \% \mathrm{~W} 30$ and $100 \%$ X30 as shown in Figures 4 (a) and (b). More gaps appear between the particles in the $100 \% \mathrm{~W} 30$ filtration. This is due to the higher surface charge in conjunction with the nonhomogeneity in particle size at this condition. Therefore, the particles tend to be forced apart from each other making the cake more porous. The cake was more compact for $100 \%$ X30 since the particles have a lower surface charge compared to the W30 silica and the particle size is more uniform. This finding was supported by the surface roughness values shown in Table 5 where $100 \%$ X30 has a smaller surface roughness when compared to the $100 \% \mathrm{~W} 30$ cake surface, which indicates that the cake is less porous than the $100 \%$ W30. Again, these two images explain the trend of the filtration obtained at different compositions at $\mathrm{pH} 9$, where the fastest filtration is given by $100 \% \mathrm{~W} 30$ and the slowest rate is given at $100 \% \mathrm{X} 30$.

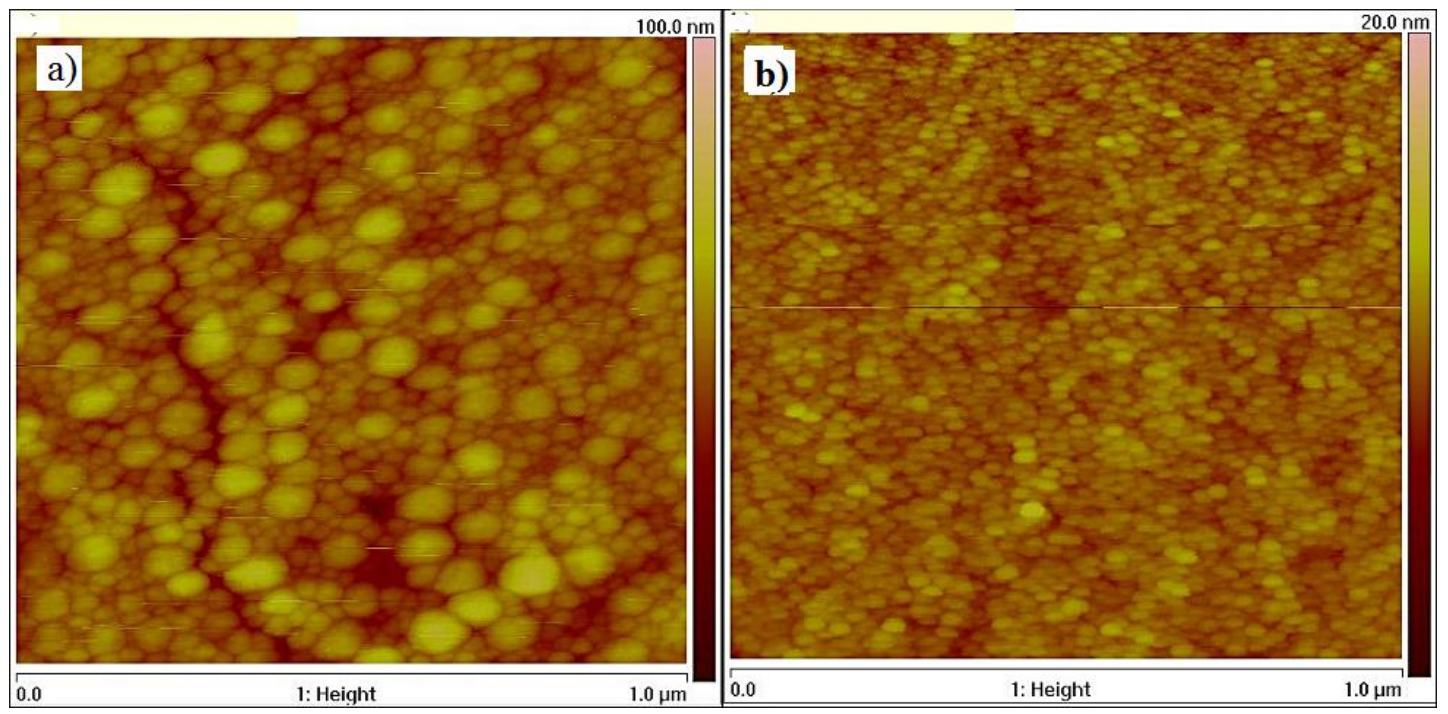



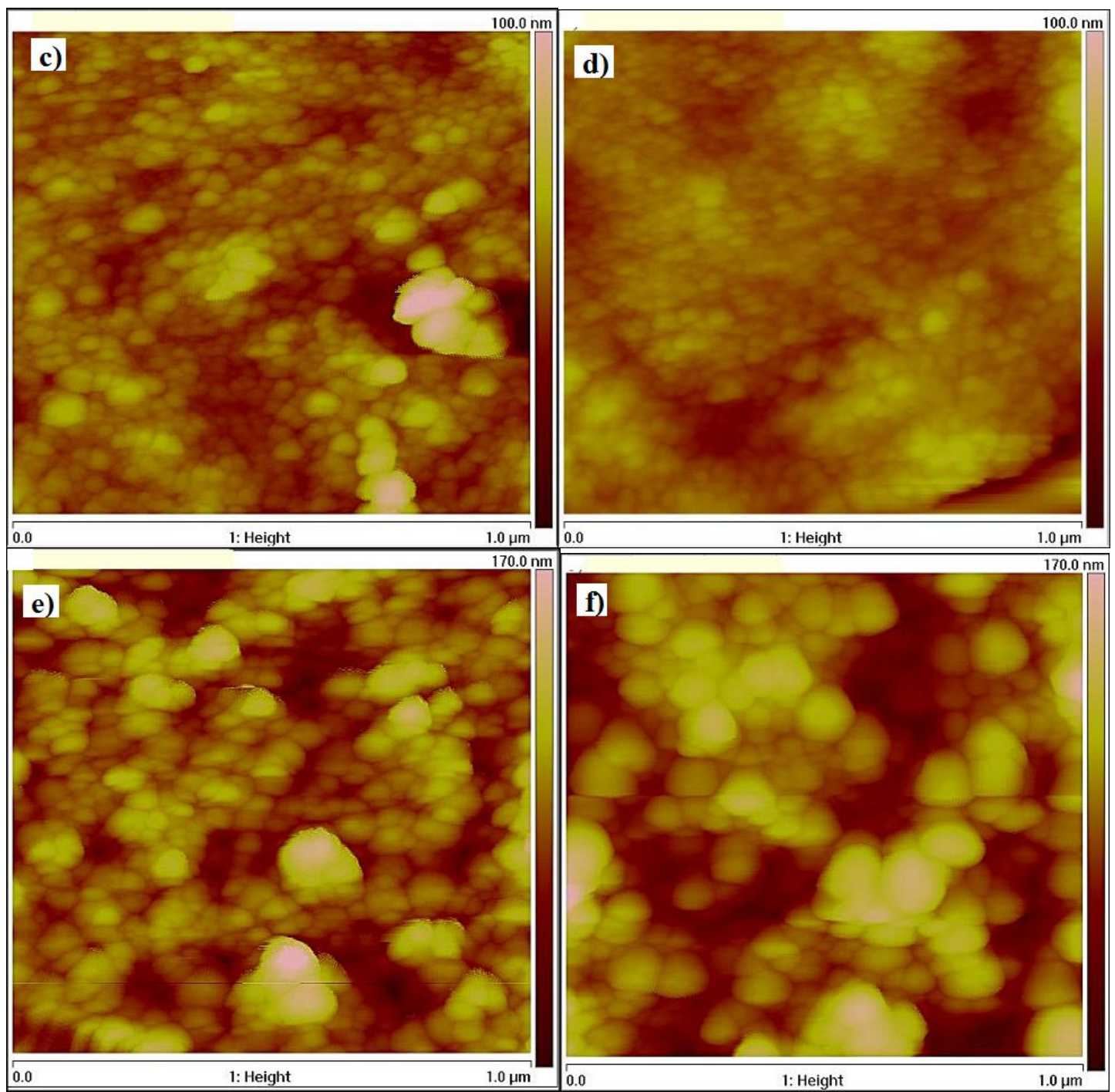

Fig 4: AFM images on the cake surface yielded from the filtration at $\mathrm{pH} 9$ for a)W30 and b)X30, at $\mathrm{pH} 6$ for c) $80 \% \mathrm{~W} 30$ and d) $100 \% \mathrm{X} 30$ and at $\mathrm{pH} 4$ for e) $80 \% \mathrm{~W} 30$ and f) $100 \% \mathrm{~W} 30$

Table 5: Surface roughness of the cake obtained at $\mathrm{pH} 9,6$ and 4, $0.03 \mathrm{M} \mathrm{NaCl}$.

\begin{tabular}{|l|l|l|}
\hline Sample & $\mathbf{p H}$ & $\begin{array}{l}\text { Surface roughness } \\
\boldsymbol{R}_{q}(\mathbf{n m})\end{array}$ \\
\hline $100 \% \mathrm{~W} 30$ & 9 & 8.16 \\
\hline $100 \% \mathrm{X} 30$ & 9 & 3.37 \\
\hline $80 \% \mathrm{~W} 30$ & 6 & 12 \\
\hline $100 \% \mathrm{X} 30$ & 6 & 8.88 \\
\hline $80 \% \mathrm{~W} 30$ & 4 & 26.7 \\
\hline $100 \% \mathrm{~W} 30$ & 4 & 35 \\
\hline
\end{tabular}

Figures 4 (c) and (d) depict the AFM images for the cakes formed at feed compositions of $80 \% \mathrm{~W} 30$ and $100 \%$ X30 at $\mathrm{pH}$ 6. The images show that the cake was flatter for $100 \%$ $\mathrm{X} 30$ compared to $80 \% \mathrm{~W} 30$, as the measured surface roughness at $100 \%$ X30 was smaller when compared to $80 \%$
W30 (see Table 5). The particles in the $80 \%$ W30, cluster to each other due to the lower surface charge at pH 6 making the surface become rougher. As a result the particles deposit randomly at this condition and build a higher cake layer compared to $100 \%$ X30 and give a maximum flux decline in 
the filtration experiments. Hence, this also promotes the filling of interstices in the W30 filter cake in the polydisperse mixture which will increase the cake resistance (McDonogh et al. 1998). This has been proved by the cake thickness measurements given in Table 3, where the $80 \%$ W30 shows a greater cake thickness when compared to the $100 \%$ X30.

At $\mathrm{pH} 4$ and $0.03 \mathrm{M} \mathrm{NaCl}$, the AFM image analysis was carried out for the filter cake at compositions of $80 \% \mathrm{~W} 30$ and 100\% W30 as shown by Figures 4 (e) and (f). Similar to $\mathrm{pH} \mathrm{6,} \mathrm{the} \mathrm{same} \mathrm{composition,} \mathrm{80 \%} \mathrm{W30,} \mathrm{has} \mathrm{given} \mathrm{the}$ slowest filtration rate at $\mathrm{pH} 4$. However, the cake found at $\mathrm{pH} 4$ is rougher when compared to the cake formed at $\mathrm{pH} 6$, where the cake at $\mathrm{pH} 4$ gave a roughness value $55 \%$ greater when compared to $\mathrm{pH} 6$ at the same composition. This might due to more particles clustering to each other at the much lower surface potential due to the decrease in $\mathrm{pH}$ and hence surface charge. The attractive force dominates the total interaction at the lower $\mathrm{pH}$ (Bowen and Jenner 1995) resulting in the particles being closer to each other. The filtration rate at feed concentrations of $100 \% \mathrm{~W} 30$ and $100 \% \mathrm{X} 30$ are quite similar at $\mathrm{pH} 4$, but the $100 \% \mathrm{~W} 30$ was chosen for AFM study since this composition was quite similar to that which gave the lowest filtration rate $(80 \%$ W30). Therefore, the effect of a small change in composition can be studied. The findings reveal that addition of a small amount of X30 particles can alter the particle arrangement in the cake structure causing an enhanced in cake compactness and resulting the decreases in surface roughness as depicted in Table 5.

\subsection{Direct Comparison between the AFM and SEM}

\section{Images}

The cake layer obtained from the filtration of $100 \%$ X30 at pH 9 was chosen for direct comparison between the SEM and AFM images. This was because the X30 filter cake was smoother so the AFM tip can handle the surface very well. However, the cake obtained from the $100 \%$ W30 solution is much rougher and the tip has a risk of breaking when it scans over the surface.

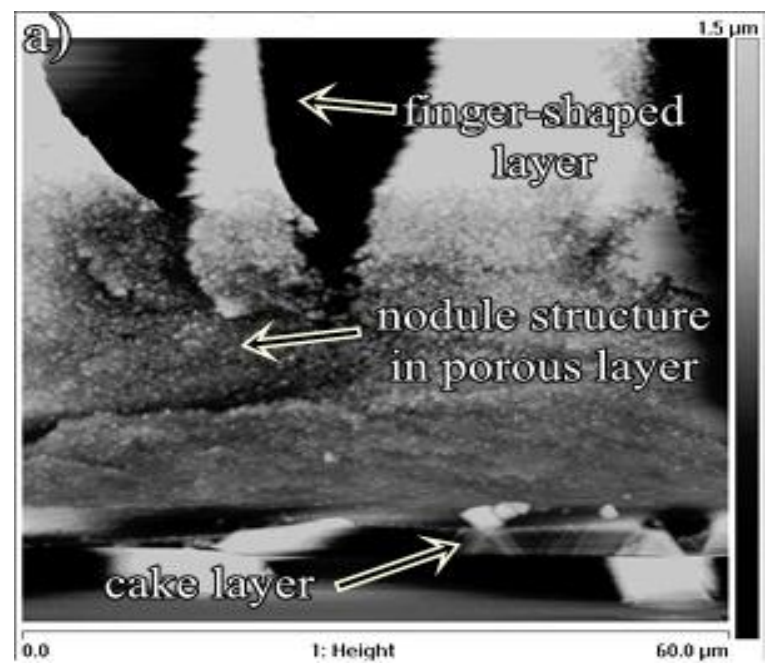

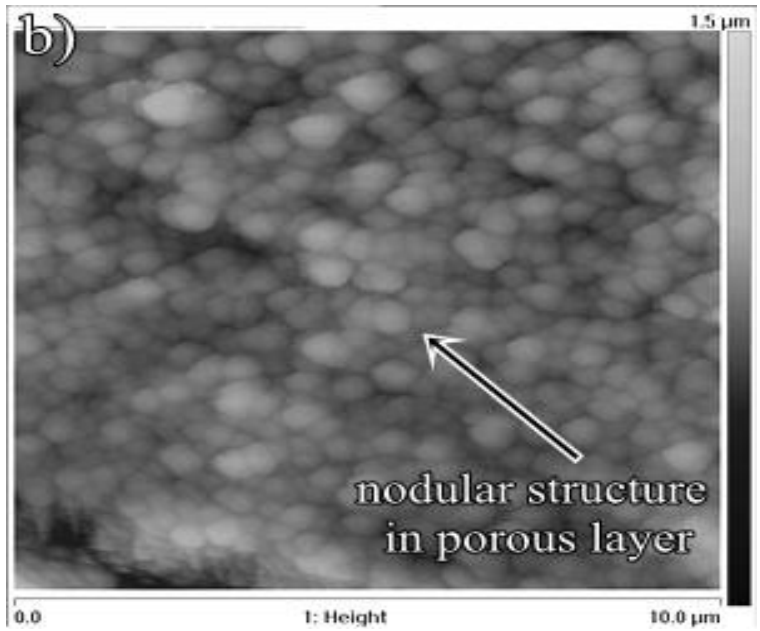

Fig 5: AFM Crosss section topographical image of the a) 60um image of membrane fouled with $100 \%$ X30 silica, b)

10 um image of membrane fouled with $100 \%$ X30 silica

Figures 5 (a) and (b) show the AFM image for the cross section of the membrane fouled by X30 particles. Figure 5 (a) shows that membrane was made of finger like macro voids and nodular structures. Khulbe et al. (2006) reported the image of the cross section for the hollow fiber membranes by AFM, and the studies confirm the existence of finger like macro voids and nodular structures. The AFM picture in Khulbe et al.'s (2006) study was taken at 3x3 $\square \mathrm{m}^{2}$ but the image is not well defined. The AFM images presented in this study represent the first time that good images of the cross sectional area for a fouled membrane have been obtained, even at higher scan areas in the range of $10 \times 10 \square \mathrm{m}^{2}$ to $60 \times 60 \square \mathrm{m}^{2}$. Figure 5 (b) shows the close up view of the nodule structure at a scan area of $10 \times 10 \square \mathrm{m}^{2}$. The nodules surface looks very rough which was due to the fabrication process in manufacturing to form the air gap structure (Khulbe et al. 2006).

The surface roughness data for the different areas labelled in Figure 5 (a) are shown in Table 6 in order to show that the different composition in all these sections can be quantified in terms of surface roughness. The cake layer has given the highest surface roughness when compared to the finger shaped layer and nodule structure. However, it should be noted that the surface roughness for the cake in this case was not the same as the surface roughness from the top view as this image represents the cross section area. Therefore, the roughness of the cake formed here was affected by the breaking process involved in preparing the sample, so the surface became far rougher when compared to the top view surface roughness.

Table 6: Surface roughness of various areas of the fouled membrane

\begin{tabular}{|l|l|}
\hline Section & Surface roughness $\boldsymbol{R}_{\boldsymbol{q}}(\mathbf{n m})$ \\
\hline Finger shaped layer & 151 \\
\hline Porous layer & 105 \\
\hline Cake layer & 263 \\
\hline
\end{tabular}


The image of the cake layer in Figure 5 (a) was not very clear. Phase imaging, which is a variant of tapping mode AFM imaging, was employed as this type of imaging can be used as an enhancement technique to detect variations in composition and also to provide a clearer observation of fine features which can be obscured by rough topography. Figures 6 (a) and (b) show the phase images of Figure 5 (a). These phase images clearly show the differences in surface composition which consists of a layer of finger shaped structures, porous structures (nodule layer) and cake layer as labelled in Figure 6 (a). The AFM Nanoscape software application allows the thickness measurement for the cake layer and porous structure in the AFM images as shown in Figure 6 (b). The cake thickness areas are labelled as $p$ and $q$, and the porous structure thicknesses are labelled as $r$ and $s$. All values labelled in Figure 6 (b) are summarized in Table 7. The average thickness for the cake layer and porous structure was $6.45 \mu \mathrm{m}$ and $25.34 \mu \mathrm{m}$ respectively.

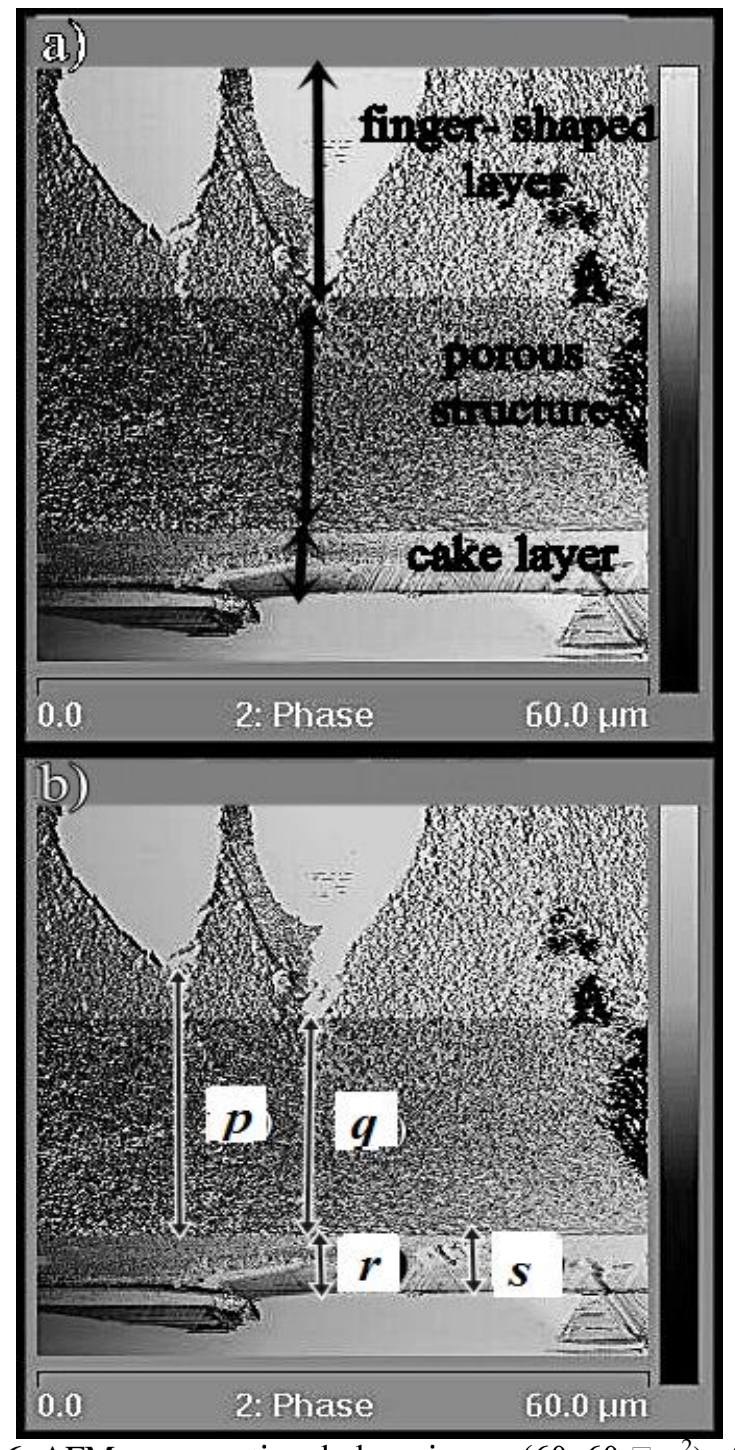

Fig 6: AFM cross-sectional phase image (60x60 $\left.\square \mathrm{m}^{2}\right)$ of the fouled membrane for $100 \%$ X30 at pH 9: a) image with structures labelled, b) thickness of the cake layer and porous structure measurement.
Table 7: Measurement of cake layer and porous structure thickness

\begin{tabular}{|l|l|l|}
\hline Label & Area & Thickness $(\boldsymbol{\mu m})$ \\
\hline$p$ & Cake layer & 6.28 \\
\hline$q$ & Cake layer & 6.63 \\
\hline$r$ & Porous layer & 25.7 \\
\hline$s$ & Porous layer & 24.9 \\
\hline
\end{tabular}

In contrast to AFM images, the images from the SEM analysis are more distinctive for observing the existence of the different layers shown in Figures 7 (a) and (b). The average thickness for the cake layer obtained from the SEM image was $6.39 \mu \mathrm{m}$. It should be noted that the cake layer obtained for direct comparison for SEM-AFM analysis was thicker when compared to the cake measured in Table 2 for $\mathrm{X} 30$ at $\mathrm{pH}$ 9. This was because the procedure to obtain the cake layer was slightly different between these two experiments.

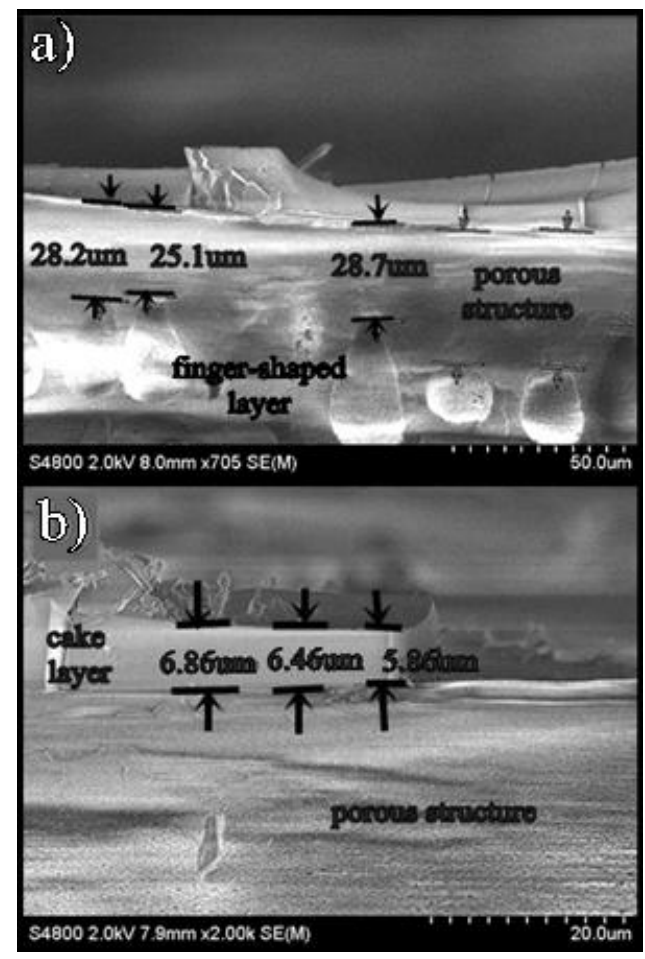

Fig 7: Cross sectional image for the SEM with the same sample use in the AFM cross section where ; a) Label diagram , b) Cake thickness

For direct comparison analysis, the cake was collected after all the solution was filtered through in order to avoid the cake layer been washed away from the membrane surface. As a result, the cake obtained from this analysis is 50 times thicker when compared to the cake measured in Table 2 for $100 \%$ X30. However, the cake was still not as thick as the amount predicted theoretically. The average thickness for the porous structure is $27.65 \mu \mathrm{m}$. A better image of the porous structure and the finger shaped layer are visible in the SEM images due to the limitation of the tips in AFM to reach the area which was deeper than the surrounding area. 


\section{CONCLUSION}

As a conclusion, the AFM images confirm the current findings obtained from the SEM regarding the W30 and X30 silica particles. There is not much difference in the thickness for the cake or porous structures measured using AFM or SEM. However, the imaging process is much easier with the SEM compared to the AFM as the surface roughness for the cross sectional area of the membrane is very rough. This is due to the limitation of the tip in AFM to reach this area especially for the finger shaped regions. Meanwhile with SEM, as the beam can travel through this surface this leads to this method being more successful for studying the cross section of the membrane. However, the phase image which was obtained by AFM also showed the different structures. Hence, AFM can provide data such as surface roughness, $3 \mathrm{D}$ images and $\mathrm{z}$-scale data which is very useful in data analysis. Nonetheless, sample preparation techniques before imaging the cross section in AFM and SEM need to be improved in order to consistently produce high resolution images of the cross section membranes and filter cakes.

\section{ACKNOWLEDGEMENTS}

We would like to thank to University Malaysia Pahang for funded a scholarship for Nor Hanuni Ramli

\section{NOMENCLATURE}

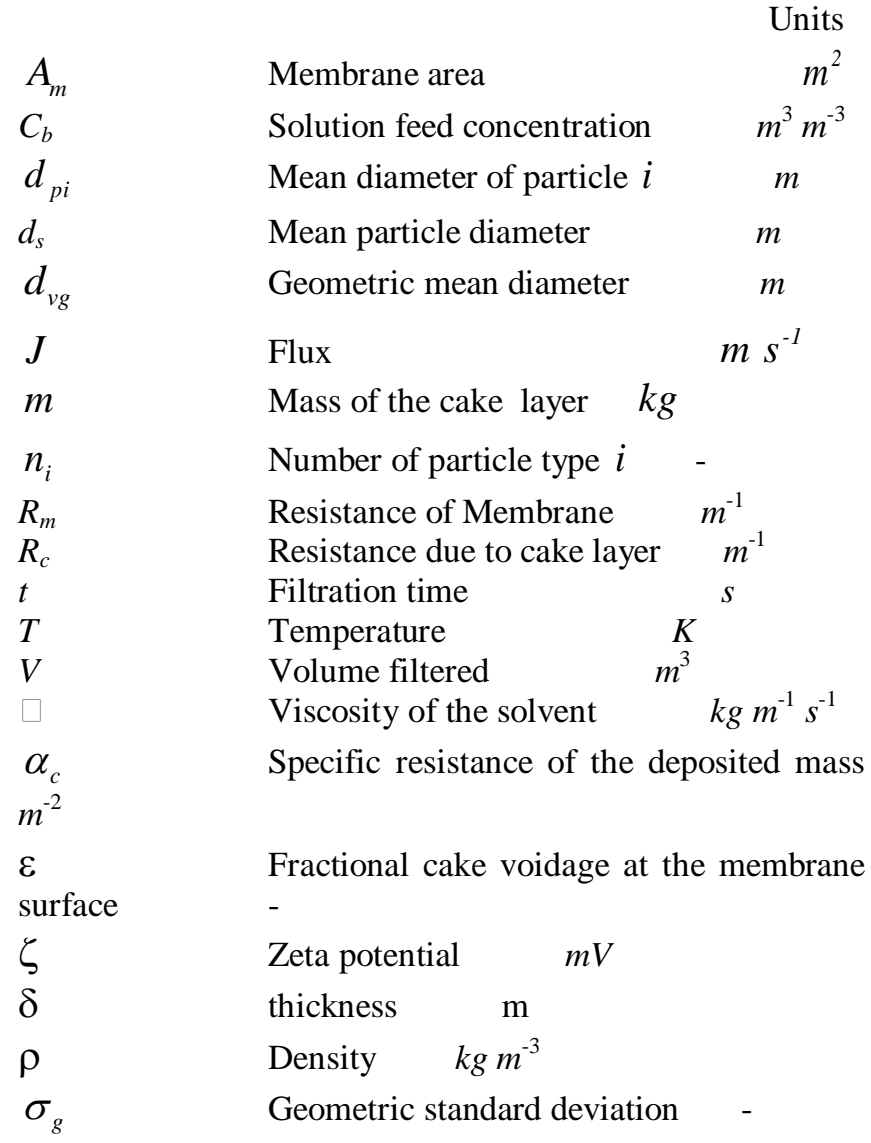

\section{REFERENCES}

[1] Bowen, W. R., and Doneva, T. A. (2000). Atomic force microscopy studies of nanofiltration membranes: surface morphology, pore size distribution and adhesion. Desalination 129, 163172.

[2] Bowen, W. R., and Jenner, F. (1995). Dynamic ultrafiltration model for charged colloidal dispersions:A Wiegner-Seitz Cell approach. Chemical Engineering Science, 50(11), 1707-1736.

[3] Bowen, W. R., and Williams, P. M. (1996a). Dynamic ultrafiltration model for proteins: A colloidal interaction approach. Biotechnology and Bioengineering 50, 125-135.

[4] Dickinson, E. (1979). Polydispersity and osmotic pressure of stable ordered colloidal dispersions. Journal of the Chemical Society, Faraday Transactions 75(2), 466-473.

[5] Endo, V., and Alonso, M. (2001). Physical Meaning of Specific Cake Resistance and Effects of Cake Properties in Compressible Cake Filtration. Filtration \& Separation, 38(7), 42-46.

[6] Khulbe, K. C., Feng, C., Matsuura, T., and Khayet, M. (2006). AFM images of the cross-section of polyetherimide hollow fibers. Desalination, 201, 130-137.

[7] McDonogh, R. M., Fane, A. G., Fell, C. J. D., and Flemming, H. C. (1998). The influence of polydispersity on the hydraulic behaviour of colloidal fouling layers on membranes perturbations on the behaviour of the "ideal" colloidal layer.Colloids and Surfaces A: Physicochemical and Engineering Aspects, 138, 231-244.

[8] Norberg, D., Hong S., Taylor, J., and Zhao, Y.Surface characterization and performance evaluation of commercial fouling resistant lowpressure RO membranes Desalination, 202:45-52.

[9] Ramli, N. H., and Williams, P. M. (2012). Experimental study of the ultrafiltration for bidisperse silica systems. Desalination and Water Treatment, 42, 1-7.

Ramli, N. H. (2012). Ultrafiltration of Polydisperse Colloidal Silica Doctor Philosophy, University of Swansea.

[11] Vrijenhoek, E.M., Hong, S., and Elimelech, M. (2001) Influence of membrane surface properties on initial rate of colloidal fouling of reverse osmosis and nanofiltration membranes Journal of Membrane Science, 188:115-128.

[12] Wutzel, H., and Samhaber, W. M. (2009). Porous polymer nanoparticle layers. Desalination 240, 27 35 . 